\title{
Combining Different Forms of Professional Development to Maximise the Learning Achievements of Teachers and Students
}

\author{
Elaine Aaltonen \\ University of London, $U K$
}

\begin{abstract}
Teachers form the foundation of schools; valuing these people and human resource development is essential to provide students with a high-quality education. Probably nothing within a school has more impact on students than the personal and professional development of their teachers [1]. However, "many conventional forms of professional development are seen as too top-down and too isolated from classroom realities to have much impact on practice" [4]. This article aims at sharing how a professional development project was carried out by coworkers engaged in a Teacher Study Group (TSG), and how it was evaluated, as a means to demonstrate that TSG might be an effective form of professional development, mainly when combined with other resources. Implemented at a Brazilian private school, the project consisted in having participants of a TSG elaborating new English tests aligned with the lesson plans for elementary school grades, throughout a tenmonth period. Main focus was to enhance students' learning achievements. We chose 'Collaborative Action Research' as our methodology; and applied Thomas Guskey's 'Backward planning' [2] as our main theoretical support. Our perception about this project is that desired results were achieved; and evidences were good enough to confirm learning improvement of both teachers and students.
\end{abstract}

\section{Introduction}

In 2013, we started implementing a Continuing Professional Development (CPD) Programme in our context: the English as a Second Language (ESL) Department of a middle-size private school located in São Paulo, Brazil, which is not bilingual, but provides its pupil population of about 1,600 aged 4-17 with a structured English course.

Two years later, we created Teacher Study Groups (TSGs) to boost the program. Since then, our faculty staff's personal and professional development has become a permanent project; and the TSGs have helped leadership identify and meet the needs of the staff.
In 2016, we decided that would carry out, on the following year, a professional development activity within our Young Learners Teacher Study Group (YLE-TSG), whose participants would elaborate new English tests in alignment with the lesson plans for the elementary school grades. We set ten months (February-June and August-December/2017) as our frame. Two relevant changes planned were 'language contextualization', by exposing students to the language applied in meaningful and real contexts rather than showing them isolated items for language manipulation practice only; and 'engagement of students in dialogue about their own learning'. This way, they would be stimulated to learn actively, in English, a range of contents pertaining to different areas, rather than being taught, passively, parts of the English language, such as grammar concepts. Our research questions: "Have the intended improvement results been achieved?", and "what kind of evidences should be provided to measure their effect on students' outcomes?" We conducted our study through 'Collaborative Action Research', which is "applied research carried out by practitioners who have themselves identified a need for change or improvement" [3]. Focused on a common goal, the activity was undertaken by elementary school teachers within a TSG, and it was facilitated and evaluated by their ESL Department Coordinator (DC), who applied the principles of Thomas Guskey's Professional Development Evaluation Model. [2] "Through formal evaluation it is possible to determine whether professional development activities, including workshops, seminars, study groups, collaborative planning, curriculum development, peer coaching and mentoring, are effectively achieving their purposes, because regardless of its form, professional development should be a purposeful endeavor" [4].

\section{Literature Review}

In simplest terms, evaluation is "the systematic investigation of merit or worth" [5]. "'Systematic' implies a focused, thoughtful, and intentional process. 'Investigation' refers to the collection and analysis of pertinent information 
through appropriate methods and techniques. 'Merit or worth' denotes appraisal and judgment" [6]. Thomas Guskey claims that effective professional development evaluations require the collection and analysis of five critical levels of information [4]. Level 1 identifies participant's reactions to the professional development experience. Level 2 focuses on measuring the knowledge and skills gained by participants. At level 3, the focus is on the organization's resources necessary for the success of the activity. At level 4, the aim is to find out whether the knowledge and skills that the participants acquired make a difference in their practice. Level 5 addresses the impact of the professional development on students' learning. "The particular student learning outcomes of interest depend, of course, on the goals of that specific development effort" [4]. Yet, three implications that stem from this model must be considered to succeed with it. First, each of the levels is important; all information gathered at level 1 is essential data for ensuring the quality of the professional development activity. Second, tracking effectiveness at one level does not determine the impact at the next. Third and maybe the most important implication is that the order of these levels must be reversed when professional development aims at improving students' learning.

As stated by Guskey, "we must plan backward, starting where we want to end and then working back" [4]. This backward planning process is very important because the decisions made at each level affect those at the next. For example, the student learning improvement we intend to achieve have an influence on the type of practices and policies we should implement. Another relevant fact is that "the relationship between professional development and improvements in student learning in realworld settings is far too complex and includes too many intervening variables" [6].

Our evidences were a set of systematic information collected as the central components of the professional development activity, including a comparison between the old and new tests applied by the same group of teachers, notes taken in class observations, and the analysis of questionnaires answered by teachers. Besides Guskey's theory, we resorted to two studies to enhance our understanding about our staff's behavior and increase their motivation. Hofstede's [7] studies on how values in the workplace are influenced by culture were helpful. Through his research, he demonstrated that values which distinguish cultures could be statistically categorized into six groups ('Power Distance'; 'Individualism versus Collectivism'; 'Masculinity versus Femininity'; 'Uncertainty
Avoidance'; 'Long Term Orientation'; and 'Indulgence'). Known as 'Hofstede's Cultural Dimensions', these groups helped us identify some characteristics of the Brazilian culture that we were not perceiving rationally at work.

'Power Distance' deals with the fact that all individuals in societies are not equal; it expresses the attitude of the culture towards these inequalities amongst individuals. With a score of 69 , Brazil reflects a society that believes hierarchy should be respected and inequalities amongst people are acceptable.

At corporate environments, it is common to find one boss who takes complete responsibility. Aware of this Power Distance, the ESL DC became more assertive in helping teachers perceive the importance of taking coresponsibility and playing leadership roles within the YLE-TSG. 'Individualism versus Collectivism' addresses the degree of interdependence a society maintains amongst its members. Brazil has a score of 38 , which means that Brazilian people are integrated into strong, cohesive groups, in which their members take care of one another in exchange for loyalty. This is an important aspect at work too. Colleagues' feeling like they belong to a collectivist environment drives them toward committment and dedication aiming at better team results.

Yet, two barriers were encountered related to this dimension: miss of focus of some teachers behaving as if they were within a family context; and resistance to follow rules due to an exaggerated feeling of protection by peers.

Regarding 'Masculinity versus Femininity', a high score (Masculine) indicates that the society is driven by competition, achievement and success, a value system that starts in school and continues throughout organizational life. A low score (Feminine) means that the dominant values in society are caring for others and quality of life. A Feminine society is one where life quality is the sign of success. Brazil scores 49, a very intermediate score on this dimension. In our context, we noticed a positive balance regarding this dimension. The dimension 'Uncertainty Avoidance' addresses the way that a society deals with the fact that certain situations and the future can never be known. With a high score of 76 , Brazilians show a strong need for bureaucracy, laws and rules to make their world better and safer, as well as for good and relaxing moments in their everyday life. A set of rules was created collectively to ensure execution of planned tasks. Due to their high score in this dimension, Brazilians are also very passionate and emotional people, whose feelings are easily shown through their body language.

The 'Long Term Orientation' dimension describes how every society maintains some 
links with its own past while dealing with the challenges of the present and future, and how societies prioritise these two existential goals differently.

Normative societies score low on this dimension, and normally prefer to maintain past traditions and norms while viewing societal change with suspicion.

On the other hand, those with a culture which scores high, take a more pragmatic approach by encouraging thrift and efforts in modern education as a way to prepare for the future.

Brazil's score in this dimension is 44, which is considered intermediate. In our context, many times we perceived that the implementation of innovative actions - such as engagement of students in dialogue about their own learning were received by most teachers with a certain degree of scepticism, but once they were convinced about the effectiveness of the initiative, they started supporting it.

The dimension 'Indulgence' is defined as the extent to which people try to control their desires and impulses, based on the way they were raised. Relatively weak control is called "Indulgence" and relatively strong control is called "Restraint". Therefore, cultures can be described either as 'Indulgent' or 'Restrained'. Brazil's high score of 59 reveals it as an Indulgent society. In the Brazilian society, most people exhibit a willingness to realise their impulses and desires with regard to enjoying life and having fun; and they have a tendency towards optimism. Additionally, they place a higher degree of importance on leisure, and act as they are pleased to spend money as they wish.

The ESL DC used this knowledge to meet teachers' needs and foster a favorable climate at YLE-TSG's meetings, frequently filled up with small surprises that helped increase motivation. In addition to 'Hofstede's Cultural Dimensions', we looked into the concept of 'Hierarchy of Needs' from 'Maslow's Theory of Motivation' [8]. According to Maslow, "people are driven from within to realize their full growth potential" [10]. This ultimate goal is sometimes called 'selffulfillment' or 'self-realization', but the author named it 'self-actualization'. Maslow's 'Hierarchy of Needs' claims that human needs start with survival, then unfold in an orderly sequential hierarchical pattern that takes each individual toward continued growth and development.

His model of human needs was depicted as hierarchical levels within a pyramid as follows:

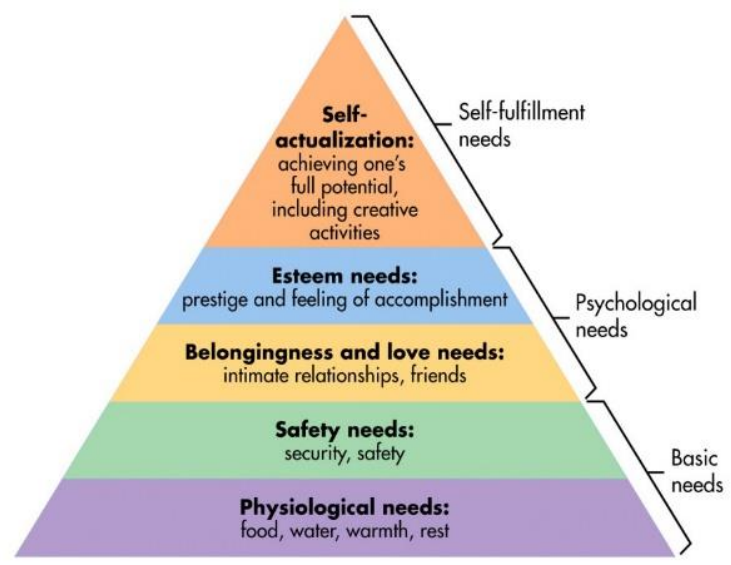

Figure 1. Five-tier model of human needs

We identified 'prepotency' related to 'Esteem needs', which was preventing a teacher to achieve 'self-actualization'. Constant dialogues with the DC helped the teacher overcome this barrier.

However, "individuals in the work environment cannot be motivated only by their own internal characteristics, perceptions and needs, nor by their environmental conditions, but by an interaction of the two" [9].

With that idea in mind, the DC had constant focus in helping teachers become more aligned with the culture of the institution, while they were developing themselves.

\section{Methodology}

This study was undertaken through 'Collaborative Action Research'.

Throughout collaborative action research activity, participants of the YLE-TSG - five elementary school teachers and their DC - met frequently to set goals, plan, engage in discussions, and make decisions about interventions needed, data collection, data analysis and report writing.

Almost simultaneously, while being the study group main leader, the DC focused on investigating whether the professional development activity was achieving its desired results, which was enhancement of the English tests as a means to improve students' learning.

The DC followed the action research cycle by 'identifying the problem'; 'setting a goal'; 'implementing a plan of action'; and 'evaluating'. As stated by Denscombe [10], "the aim is to arrive at recommendations for good practice that will tackle a problem or enhance the performance of the organization and individuals through changes to the rules and procedures within which they operate". Research questions were the following: "have the intended 
improvement results been achieved?", and "what kind of evidences should be provided to measure its effect on students' outcomes?". Evaluation of the professional development activity undertaken followed the principles of Guskey's 'backward planning', so we displayed and analysed gathered information in a reversed order. At Level 5, which addresses the activity's impact on students' learning outcomes, evidences were demonstrated through the following: a comparison between the old and the new written and speaking tests; the 5th grade students' performance in an external examination (YLE Exam by Cambridge University); feedbacks by teachers.

Table 1. Main characteristics of the English tests applied to 2nd-5th grade elementary school students in 2016 and 2017

\begin{tabular}{|c|c|c|}
\hline \multirow{5}{*}{$\begin{array}{l}\text { YLE } \\
\text { Starters } \\
\mathbf{2 0 1 6}\end{array}$} & \# of students who & Percentage \\
\hline & $\begin{array}{l}\text { took the exam: } 30 \\
\text { (out of 93) }\end{array}$ & $32 \%$ \\
\hline & $\begin{array}{l}\text { got the } 5 \text { colored } \\
\text { shields* related to } \\
\text { Reading and use of } \\
\text { English }\end{array}$ & $42 \%$ \\
\hline & $\begin{array}{l}\text { got the } 5 \text { colored } \\
\text { shields related to } \\
\text { Listening }\end{array}$ & $55 \%$ \\
\hline & $\begin{array}{l}\text { got the colored } \\
\text { shields related to } \\
\text { Speaking }\end{array}$ & $70 \%$ \\
\hline \multirow{5}{*}{$\begin{array}{l}\text { YLE } \\
\text { Starters } \\
\mathbf{2 0 1 7}\end{array}$} & \# of students who & Percentage \\
\hline & $\begin{array}{l}\text { took the exam: } 83 \\
\text { (out of } 121 \text { ) }\end{array}$ & $68 \%$ \\
\hline & $\begin{array}{l}\text { got the } 5 \text { colored } \\
\text { shields* related to } \\
\text { Reading and use of } \\
\text { English }\end{array}$ & $75 \%$ \\
\hline & $\begin{array}{l}\text { got the } 5 \text { colored } \\
\text { shields related to } \\
\text { Listening }\end{array}$ & $72 \%$ \\
\hline & $\begin{array}{l}\text { got the colored } \\
\text { shields related to } \\
\text { Speaking }\end{array}$ & $85 \%$ \\
\hline
\end{tabular}

Data shown in Table 1 confirm qualitative improvement of both tests. A major change into the written test's format, for instance, was the inclusion of text comprehension, so that vocabulary and grammar structures learned started being contextualized.
Table 2. Results achieved by 5th graders in YLE Starters Exam taken in 2016 and 2017

\begin{tabular}{|c|c|c|}
\hline Test & Year & Characteristics \\
\hline \multirow[t]{2}{*}{ Written } & 2016 & $\begin{array}{l}\text { - unclear or too complex } \\
\text { headings } \\
\text { - vocabulary and linguistic } \\
\text { structures descontextualized } \\
\text { - lack of text comprehension } \\
\text { - few and not meaninful } \\
\text { illustrations } \\
\text { - too many exercises } \\
\text { requiring students to draw }\end{array}$ \\
\hline & 2017 & $\begin{array}{l}\text { - language employed in } \\
\text { headings appropriate to } \\
\text { students age range } \\
\text { - vocabulary and linguistic } \\
\text { structures contextualized } \\
\text { - at least one text } \\
\text { comprehension related to } \\
\text { subject learned in class } \\
\text { - more and meaningful } \\
\text { illustrations } \\
\text { - no more exercises } \\
\text { requiring drawings }\end{array}$ \\
\hline \multirow[t]{2}{*}{ Speaking } & 2016 & $\begin{array}{l}\text { - format: a dialogue to be } \\
\text { role-played in pairs (most of } \\
\text { the time the same studied in } \\
\text { class) } \\
\text { - lack of test script for } \\
\text { teachers to follow during the } \\
\text { test } \\
\text { - lack of speaking test } \\
\text { evaluation form } \\
\text { - lack of use of props }\end{array}$ \\
\hline & 2017 & $\begin{array}{l}\text { - format: } 2-3 \text { speaking tasks } \\
\text { based on real situations of } \\
\text { interlocution between } 2-3 \\
\text { people (to be performed by } \\
\text { students) and } 1 \text { situation } \\
\text { similar to an interview (to be } \\
\text { done through teacher- } \\
\text { student interaction) } \\
\text { - test script for teachers to } \\
\text { follow during the test } \\
\text { - speaking test evaluation } \\
\text { form } \\
\text { - use of props and other } \\
\text { visual aids to illustrate } \\
\text { speaking tasks }\end{array}$ \\
\hline
\end{tabular}

In Table 2, 'enhancement of students learning' is reflected in the $5^{\text {th }}$ graders' performance in the external examination. In 2016, thirty students took the exam, and $42 \%$ scored 100 in the reading and writing test. In 2017, 93 took the exam, and $75 \%$ scored $100 \%$ in the same test. Feedbacks by 
two teachers who taught $4^{\text {th }}$ and $5^{\text {th }}$ graders in 2016 and 2017 shared similar perceptions on the achievement of desired goals:

- "Overall, students became more interested and participative in my classes when we started using new material, new approach and new tests", (Teacher A);

- "At this age range, children are full of joy, and wish to learn, but many of them are also full of criticism. Confirmation that we were meeting their expectations came when they improved performance in class, and praised the new material and new tests" (Teacher B).

Level 4 focuses on verifying whether the knowledge and skills acquired by teachers have made a difference in their practices.

Evidences were reached through notes taken at interviews between teachers and the DC, twice a month throughout 2017, as well as in class observations.

The key to obtain relevant information consists in specifying clear indicators of both the degree and the quality of the implementation. While observing the teachers or talking to them privately, the DC aimed to find out to which extent they were applying knowledge and skills gained through the development activity. A recurrent subject at meetings was the importance of involving students in frequent conversations about their learning, since this is a powerful tool to help them achieve a successful learning experience.

"Dialogue requires participants to be engaged in dynamic talk that builds on the ideas and perspectives of all; it is a process in coconstruction" [11]. Engagement of each student in dialogue about their own learning started being part of their class routines. Royce Sadler [12] identified three questions that frame well this type of conversation: "Where am I going? Where am I now? How can I close the gap?".

One of the teacher's main role in class is to help each student bridge the gap between the point in which he/she is and where he/she needs to be. Once the teacher is aware of that, it becomes easier to identify specific practices to meet each student's needs, such as re-teaching topics and re-sorting students in small groups to encourage work connected to peers' strengths.

We noticed students became used to talking about what they had learned or should have learned in class. Based on that information, we improved our "recuperation program", through which both teachers and students started working in partnership to overcome learning gaps. At level 3, which addresses to how well the ESL DC facilitated the work produced by the YLE-TSG, evidences were obtained through the analysis of answers by teachers to a questionnaire featuring questions such as "were sufficient resources made available?"; "Did this professional development activity affect the organization's climate?".

At Level 2, which aims at measuring the knowledge acquired by the group of teachers, evidences were obtained through a set of instruments: teachers' oral and written reflections expressed in different moments; and paper-andpencil evaluations.

At level 1, whose focus is on the participants' reactions to the professional development experience, evidences were reached through the answers to a questionnaire handed out in the last YLE-TSG meeting as well as notes taken by the DC. Questions included the following: "Did the activity undertaken meet your expectations? Why?"; "Did you improve your knowledge and skills?".

\section{Forms of Professional Development Applied}

The major forms of professional development include “'Training', 'Observation/Assessment', 'Involvement in a development/improvement process', 'Study Groups', 'Inquiry/action research', and 'Mentoring'", [4].

'Training' is the most common form of professional development, and it is not a synonym of it as many educators may consider.

"The best training sessions are organised with clear objectives or participants outcomes in mind" [4]. Training formats range from presentations, workshops, seminars, lectures, to colloquia and discussions; and involve a presenter or a team of presenters whose purpose is to share ideas and expertise through various group-based activities. "Effective training generally features exploration of theory, demonstration and modelling of skills, simulated practice, feedback about performance, and coaching in the workplace" [13].

The teachers engaged in the YLE-TSG participated in an in-service training focused on the new didactic material adopted, before starting the work within the study group; and the knowledge and skills improved with it had a positive impact on their discussions and decisions while they were undertaken the project. 'Observation/Assessment' - which can be either by observing others or being observed and receiving feedback - is one of the best ways to promote learning within an educational setting.

"Observations that are well planned, focus on specific issues, and provide follow-up to document improvements are generally the most effective" [4]. This was one of the main forms of 
professional development applied by the DC, who created the habit of observing all the teachers in class at least once a month, depending on the demand, taking notes in an specific form and then giving each individual a formative feedback about their performance at their private meetings. "Analysing and reflecting on this information can be a valuable means of professional growth" [4]. "The major advantage of the observation/ assessment model is that it provides important benefits to both observer and the one being observed" [14].

The observer gains professional expertise by watching a colleague, preparing the feedback, and discussing common experiences. On the other hand, the teacher being observed gains new insights, has the opportunity to exchange ideas/practices and receives a helpful feedback [15].The 'Involvement in a Development/Improvement Process' helps the participants not only increase their knowledge and skills, but also encourages them to enhance their ability to work collaboratively and to participate actively in the decison-making process. "To be effective, participants in the development/improvement process must have ready access to appropriate information and expertise so that they can make knowledgeable and well-reasoned decisions" [16]. A problem related to this form of professional development ocurred when some YLE-TSG participants who were carrying out the project tried to persuade their colleagues to support their opinions, which were not based on research evidence nor by the best practice.

Through open dialogue, the DC proposed discussions focused on raising awareness about the importance of supporting opinions and beliefs with research-based evidence, as well of relating to one another in an ethical and respectful manner.

"The overwhelming majority of educators are thoughful, inquiring individuals who are inclined to solve problems and search for answers to pressing questions" [4]. The 'Inquiry/Action Research' form of professional development enable them to do that.

"This model is based on the belief that educators have the ability to formulate valid questions about their own practice and pursue effective answers to those questions" [17]. By engaging the YLE-TSG participants in the role of researchers, we could narrow the gap between research and practice. The 'Study Groups' model of professional development was the most important component of the ESL department's CPD Programme.

"The major functions of study groups are to facilitate implementation of curricular and instructional innovations, collaboratively plan school improvement efforts, and study research on teaching and learning" [18]. The way the YLE-TSG was structured, i.e as a homogeneous group formed with elementary school teachers with similar experiences and common interests, and led by the same person (the DC) throughout a ten-month frame, rather than having rotating leadership, which is usual, seemed to have contributed for the successful implementation of other forms of professional development within a short period of time. "Study groups bring focus and coherence to improvement efforts, especially if groups are carefully structured, well trained, and well supervised" [4].However, it is unlikely that a single form of professional development will be effective for all professionals. Therefore, "a professional development plan based on a combination of models can take advantage of the positive attributes of several resources" [4].

Our elementary school teachers were involved in an improvement activity, which they carried out through collaborative action research within their study group; the ESL DC (group leader) made frequent use of class observations followed by feedbacks at private meetings; and also evaluated the project through action research. It is relevant to bear in mind that all these forms of professional developmment require the commitment of substantial amount of time from all the professionals, who need to conciliate their schedules in order to meet everyone's needs. Yet, the results can be amazingly good. "Combining models in thoughtful ways can provide a highly effective means to professional growth and improvement at both the individual and organizational levels [4].

\section{Conclusion}

The more time teachers spend on CPD, the more significantly they change their practices, especially when they are motivated, their work routine is planned, and their performance, continuously evaluated.

"Accompanying recognition of the importance of professional development, however, are serious concerns about the effectiveness of much professional development practice" [4]. A professional development plan grounded in day-to-day teaching practice, which uses student data to guide instruction, and combines different forms of professional development seems to be more adequate to become a major tool to maximising the learning achievements of both teachers and students.

Involving teachers in a professional development activity through a study group led to class observation, assessment, peer coaching, and a series of inquiry/action research projects. 
The five participants and the DC reported that they learned a great deal from the professional development activity undertaken, which contributed to an increase in their motivation and committment with their personal and professional development.

In addition to that, all of them noticed that the evidences of the students' performance, which were collected and analysed, confirmed their perception that the development achieved by teachers, through the professional development activity undertaken, had a positive impact in their students' performance.Guskey's backward approach helped increase efficacy in the evaluation of the professional development activity.Insights from Hofstede's research helped increase understanding about how people's behavior is affected by culture in the work environment. Leadership learned that, in order to sustain long-term evolution of teachers' motivation, should find a facilitative approach to encourage and support them in their efforts to grow and develop their ways of perceiving their work environment, their personal and professional goals and beliefs.

This facilitative approach might, for instance, seek to encourage teachers to be always moving up Maslow's hierarchy of needs over time, always in the direction of self-actualization.

Feedback from elementary school teachers claimed that developing content for the same grades in which they were teaching allowed them to produce better quality work in a collaborative nature. The DC noted that information sharing, relationship and collective learning building, role clarity and research-based resource support were important aspects for teachers development through study groups. Finally, considering that strategic human resource management is 'context-sensitive' rather than 'context-free', it is relevant to emphasize that leaders should know well their staff members and have the ability to select and adapt policy, methods and strategies that better fit their contexts.

\section{References}

[1] Barth, R. Improving Schools from Within. San Francisco: Jossey-Bass, 1990

[2] Guskey, T. R. The Backward Approach. Journal of Staff Developement, 18(2), 36-40., 2000.

[3] Bell, J. and Waters, S. Doing your research project. Open University Press. 6th edition, 2014.

[4] Guskey, T. R. Does it make a difference? Evaluating Professional Development". Corwin Press., 2000.
[5] Joint Committee on Standards for Educational Evaluation. The program evaluation standards. Thousand Oaks, CA: Sage, 1994

[6] Guskey, T. R., \& Sparks, D. Exploring the Relationship between Staff Development and Improvements in Student Learning. Journal of Staff Development, 17, 34-38, 1996.

[7] Hofstede, G. Cultural differences in teaching and learning. International Journal of Intercultural Relations, 1986.

[8] Maslow, A. H. A Theory of Human Motivation. Midwest Journal Press, 1943, 1954, 2016.

[9] Anja Kollmuss \& Julian Agyeman. Mind the Gap: why do people act environmentally and what are the barriers to pro-environmental behavior? Tufts University, Medford, MA, USA, 2002.

[10] Denscombe, Martyn. Ground Rules for good research. Open University Press, 2002.

[11] Lodge, C. Engaging student voice to improve pedagogy and learning. International Journal of Pedagogies and Learning 4 (5) 4-19, 2008.

[12] Sadler, Royce. Formative Assessment: revisiting the territory. Faculty of Education, Griffith, University, Queensland, Australia, 1998.

[13] Joyce, B. \& Showers, B. Student achievement through staff development: fundamentals of school renewal. New York: Longman, 1995.

[14] Showers, B. \& Joyce, B. The Evolution of Peer Coaching, Educational Leadership, 1996.

[15] Ackland, R. A review of peer coaching literature. Journal of Staff Development, 1991.

[16] Guskey, T.R. \& Peterson, K.D. The Road to Classroom Change. Educational Leadership, 1996.

[17] O’Hanlon, C. Professional Development through Action Research. Philadelphia: Falmer, 1996.

[18] Murphy, C. Finding time for faculties to study together. Journal of Staff Development, 1997.

\section{Acknowledgements}

I would like to thank Rupert Higham, Liz Wood, Yiasemina Karagiorgi, Domini Bingham and Trevor Male, professors from the Master's Programme in Applied Educational Leadership at the University of London, for their generous guidance and excellent academic support.

Also, I would like to extend my gratitude to my husband Alex Aaltonen for his constant support, and to my children Ana Luíza and Davi for being a source of joy in my life. 